\title{
Comorbid Psychiatric Disorders in Alcohol Dependence: A Control Study
}

Suprakash Chaudhury ${ }^{1 *}$, Daniel Saldanha ${ }^{1}$, Rajeev Saini' ${ }^{2}$, Chetan Diwan ${ }^{3}$, Vivek Pratap Singh ${ }^{1}$ and Vinayak Pathak ${ }^{1}$

${ }^{1}$ Department of Psychiatry, Dr DY Patil Medical College, Pune, Maharashtra, India

${ }^{2}$ Department of Psychiatry, Armed Forces Medical College, Pune, Maharashtra, India

${ }^{3}$ Karve Institute of Social Service, Pune, Maharashtra, India

\begin{abstract}
Background: Though anecdotal evidence of comorbid psychiatric disorders in alcohol dependent patient abound there is lack of systematic Indian studies in this area.

Aim: To determine the type and frequency of comorbid psychiatric disorders in alcohol dependent individuals as compared with matched normal population.

Methods: This cross-sectional, hospital based, utilized the Mini International Neuropsychiatric Interview to assess 88 alcohol-dependent patients consecutively admitted to de-addiction unit of two tertiary care hospitals, one in urban area and another in rural area. A matched control group of 88 subjects from the general population were also assessed. Psychiatric diagnoses were made as per DSM IV TR criteria.
\end{abstract}

Results: Among the alcohol-dependent patients $46.59 \%$ showed personality disorders compared to $6.82 \%$ of the normal control sample. The difference was statistically significant. Depression $(10.23 \%)$, mixed anxiety and depression $(7.95 \%)$ and Adjustment disorder (7.95\%) were most prevalent, followed by dysthymia (4.55\%) and panic disorders $(4.55 \%)$ were the commonest co-morbid psychiatric disorders.

Conclusion: There is high prevalence of comorbid psychiatric disorders in patients with alcohol dependence

Keywords: Alcohol dependence; Comorbid psychiatric disorder; Depression; Mixed anxiety and depression

\section{Introduction}

Epidemiological studies indicate that out of two billion alcohol users worldwide 76.3 million (7.63\%) have at least one disorder caused by their habit. Regular consumption of alcohol has numerous negative consequences. Physical adverse effects include hepatic cirrhosis, neoplasia, gastritis, esophageal varices, pancreatitis, and diabetes mellitus, among others. Psychiatric effects include elevated rates of mood and/or anxiety disorder co morbidities, which is associated with difficulty in adhering to treatment and worse prognoses [1-3]. Alcohol use disorders (AUDs) are responsible for 5 million deaths per year [4]. AUDs also produce a significant economic burden on society, with direct and indirect costs exceeding $2 \%$ of gross domestic product [5]. Despite these negative consequences it is estimated that $78 \%$ individuals with AUDs remain untreated [6]. In India the number of alcohol consumers is estimated at more than sixty million and this has further increased in recent times [7]. Alcohol use disorders (AUDs) are a major health problem in India and probably the commonest psychiatric disorder in the general population. The presence of co-morbid psychiatric disorder in individuals with AUDs compounds the problem by increasing the burden on the health care system. In addition, comorbid psychiatric disorders in patients with alcohol dependence is associated with prolonged hospital stay, poorer treatment outcomes, increased relapse rates, suicide, homelessness, and negative impact on family [8].

The high but widely differing prevalence of comorbid psychiatric disorders in individuals with AUDs is documented by a number of large epidemiological studies. A $44 \%$ prevalence of co-morbid psychiatric disorder in persons with AUDs was seen in the Epidemiologic Catchment Area Study [9]. On the other hand in the National Comorbidity Study (NCS) individuals with an AUD had 12-months prevalence of $29.2 \%$ for mood (affective) disorders which included major depressive disorder $(27.9 \%)$ and bipolar disorder (1.9\%), while that of anxiety disorders was $36.9 \%$ which included panic disorder (3.9\%), and PTSD (7.7\%) and generalized anxiety disorder (11.6\%) [10].
Furthermore few studies have shown that co-morbid psychiatric disorders are more common in AUD who are admitted for treatment as compared to those in the general population [11], though some studies gave contradictory findings. A French hospital based study found that $42.12 \%$ out of 330 AUD patients met the diagnostic criteria for another psychiatric disorder. The comorbid psychiatric disorders included mood disorder $30.6 \%$, anxiety disorder $5.5 \%$, psychosis $4.6 \%$, and dementia $1.5 \%$ [12]. Similarly in a Spanish study involving 2300 subjects with AUD, dual disorders (meeting DSM IVTR criteria) was found that $42.2 \%$ patients, most frequently mood and anxiety disorders [13]. However, in contrast to the above, a lower prevalence of $18.5 \%$ comorbid psychiatric disorders in patients with AUD was reported from Canada [14].

In India also the results of few studies gave highly variable results of comorbidity ranging from $81 \%$ to $47 \%$. In a study of one hundred inpatients of a tertiary care psychiatric institute at Ranchi $81 \%$ of AUD patients had at least one comorbid psychiatric disorder as per ICD 10 [15]. Another hospital based study from Rohtak included 30 consecutive patients meeting the DSM-IV criteria for alcohol dependence. These patients were interviewed on structured clinical interview for DSMIV (SCID) comorbid psychiatric disorder were diagnosed in $76.6 \%$ patients including major depression (52.1\%), dysthymia (13.0\%), brief psychotic disorder (13.0\%) and alcohol induced psychotic disorder

*Corresponding author: Suprakash Chaudhury, Department of Psychiatry, Dr DY Patil Medical College, Pune, Maharashtra 411018, India, Tel: 0207805000; E-mail: suprakashch@gmail.com

Received: January 04, 2018; Accepted: March 22, 2018; Published: April 02, 2018

Citation: Chaudhury S, Saldanha D, Saini R, Diwan C, Pratap Singh V, et al. (2018) Comorbid Psychiatric Disorders in Alcohol Dependence: A Control Study. J Psychiatry 21: 442. doi:10.4172/2378-5756.1000442

Copyright: (c) 2018 Chaudhury S, et al. This is an open-access article distributed under the terms of the Creative Commons Attribution License, which permits unrestricted use, distribution, and reproduction in any medium, provided the original author and source are credited 
(21.7\%) [16]. In a study at a general hospital psychiatric unit in Imphal 100 subjects who fulfilled the DSM-IV criteria for alcohol dependence syndrome were administered the Present State Examination (PSE) for a DSM-IV diagnosis. Comorbid psychiatric disorders were present in $71 \%$ individuals including depression (26\%), phobia (16\%) GAD (8\%), other substance abuse (8\%) sexual dysfunction (4\%), schizophrenia (2\%) and OCD (2\%) [17]. A hospital based study from Thiruvalla, included 88 AUD patients out of which $66.59 \%$ met ICD 10 criteria for a comorbid psychiatric disorder including BPAD $(\mathrm{n}=18)$, Depression $(\mathrm{n}=15)$, Phobia $(\mathrm{n}=8)$, GAD $(\mathrm{n}=6)$, Schiz $(\mathrm{n}=3)$, OCD $(\mathrm{n}=1)$ and Delusional disorder $(n=1)$ [18]. Similarly, a hospital based study from Lucknow revealed that out of 37 patients meeting DSM-IV-TR criteria for alcohol dependence, $64.8 \%$ had a co-morbid psychiatric disorders including mood disorder (50.0\%), psychotic disorder (25.0\%), anxiety disorder (45.8\%), and substance use disorder 13 (54.2\%) [19]. Lastly, a study from Bareilly included 100 male patients of alcohol dependence syndrome evaluated with the Mini-International Neuropsychiatric Interview-Plus version (MINI-Plus). Overall $47 \%$ of the patients had one or more co-morbid psychiatric diagnoses including mood disorder $24 \%$, anxiety disorder $14 \%$, adjustment disorder $3 \%$, Psychotic disorder $6 \%$, and somatoform disorder $2 \%$ [20].

It is evident from the foregoing that Indian studies in this area have given highly variable results. Various reasons have been suggested to explain the lack of consistent findings in the literature including differences in diagnostic criteria (ICD or DSM), different types of AUD in the sample (abuse or dependence, during active use or remission), setting of the study (hospital or community based), and diagnostic method (clinical interview, screening test or a structured interview schedule). All the studies were at a single center, all were located in urban areas and no study was done in rural area. Structured interviews were also used by a few studies only. In view of the lack of consistent findings and the paucity of Indian literature in this area the present study was undertaken to assess the type and frequency of co-morbid psychiatric disorders in patients with DSM IV TR alcohol dependence.

\section{Material and Methods}

This was a cross-sectional, hospital based study carried out in the de-addiction units of two tertiary care teaching hospitals attached to medical college. One center was located in a metropolitan city while the other was located in a rural area, with the nearest town at a distance of $60 \mathrm{~km}$. Sample was selected by purposive sampling method. Approval for the study was obtained from the institutional ethical committee. All patients admitted for de-addiction treatment with diagnosis of alcohol dependence included in the study after obtaining their written informed consent. For the purpose of the study patients were evaluated two weeks after hospitalization.

\section{Inclusion criteria for patients}

- Alcohol dependence diagnosed as per criteria in DSM IV TR $[21]$.

- Consenting for the study.

\section{Exclusion criteria for patients}

- $\quad$ Patients with serious medical illnesses like cirrhosis of liver, hypertension and diabetes mellitus.

- Clinical evidence of dehydration and obvious malnutrition.

- Past history of psychiatric disorders or other substance use (apart from nicotine).
An equal number male control subjects matching the patients in age and sex without any physical or psychiatric disorders or substance use disorders were also studied after obtaining their written informed consent.

\section{Tools}

Socio demographic and clinical characteristics including age, marital status, education, occupation, family income, age at onset and duration of alcohol consumption were recorded on a specially designed proforma. Detailed history about the alcohol habit was obtained from the patient and from family members.

Mini international neuropsychiatric interview (MINI): MINIis a brief structured interview for arriving at a diagnosis of the major Axis I psychiatric disorders in DSM IV TR and ICD 10. In the present study it was utilized to confirm the diagnosis of $\mathrm{AD}$ and also other psychiatric comorbidities and rule out other substance dependence/abuse apart from nicotine. The MINI has acceptable validity and reliability as compared to the structured clinical interview for DSM-III-R. The major advantage of the MINI is that it can be administered in a much shorter period of time than the above referred instruments $[22,23]$.

\section{Statistical analysis}

Statistical analysis were carried out using the students ' $\mathrm{t}$ ' test, chisquare test with Yates correction and Fishers exact test as appropriate.

\section{Results}

During the period of the study 88 male patients with alcohol dependence syndrome were hospitalized and were included in the study. An equal number of age and sex matched individuals with no physical or psychiatric disorder formed the control group. Sociodemographic details of the patients with alcohol dependence and control subjects are given in Table 1. It is evident that the patients and control subjects were well matched on socio-demographic variables like age, sex, education, marital status, and socioeconomic status. Table 2 gives the details regarding the age at initiation of alcohol consumption and period of alcohol consumption of the patients. Table 3 gives the prevalence of comorbid psychiatric disorders in patients with alcohol dependence in the present study along with prevalence of psychiatric disorders in the control group.

\section{Discussion}

The past two decades has seen an increased awareness of dual diagnosis i.e., a psychiatric disorder accompanying substance use disorder that may result in diagnostic uncertainty and difficulties in management. Dual diagnosis is a topic of growing interest due to its clear impact on clinical severity. Many authors opine that "chronicity" and "treatment resistance" are the hallmarks of dual diagnoses and most sufferers are more vulnerable to experience disabilities of varying dimensions than in those with a single diagnosis [24]. It has been postulated that AUD can mimic or potentiate almost all psychopathological symptoms [25].

The present study attempted to make few methodological improvements over earlier studies. The control subjects were well matched to the alcohol dependent subjects and known patients with psychiatric disorders were excluded. A standardized diagnostic tool was used for making the psychiatric diagnosis using DSM IV TR criteria. Another strength of the present study was that a large number of individuals from rural agrarian population belonging to lower socioeconomic class were included which is similar to the general 


\begin{tabular}{|c|c|c|c|c|c|c|}
\hline \multicolumn{2}{|c|}{ Variable } & ADS Patients & Controls & $\mathrm{T} / \mathrm{X}^{2}$ & df & p \\
\hline Age in years & $\begin{array}{l}\text { Mean }( \pm \\
\text { S.D. })\end{array}$ & $\begin{array}{l}40.86( \pm \\
10.72)\end{array}$ & $\begin{array}{l}40.64( \pm \\
10.56)\end{array}$ & 0.134 & 174 & $\begin{array}{c}0.893 \\
\text { NS }\end{array}$ \\
\hline $\begin{array}{c}\text { Age } \\
\text { distribution } \\
\text { (in years) }\end{array}$ & $\begin{array}{l}21-30 \\
31-40 \\
41-50 \\
51-60 \\
61-70 \\
71-80\end{array}$ & $\begin{array}{c}11 \\
36 \\
29 \\
6 \\
3 \\
3\end{array}$ & $\begin{array}{c}11 \\
36 \\
29 \\
7 \\
3 \\
2\end{array}$ & 0 & 160 & $\begin{array}{l}1.00 \\
\text { NS }\end{array}$ \\
\hline Marital Status & $\begin{array}{l}\text { Married } \\
\text { Unmarried } \\
\text { Separated } \\
\text { Widower }\end{array}$ & $\begin{array}{c}78 \\
3 \\
5 \\
2\end{array}$ & $\begin{array}{l}80 \\
5 \\
0 \\
3\end{array}$ & 5.56 & 160 & $\begin{array}{c}0.062 \\
\text { NS }\end{array}$ \\
\hline Education & $\begin{array}{l}\text { Illiterate } \\
1-5 \text { class } \\
6-12 \text { class } \\
\text { Graduates }\end{array}$ & $\begin{array}{c}14 \\
22 \\
48 \\
4\end{array}$ & $\begin{array}{c}12 \\
20 \\
49 \\
7\end{array}$ & 1.18 & 160 & $\begin{array}{c}0.758 \\
\text { NS }\end{array}$ \\
\hline Occupation & $\begin{array}{l}\text { Farmer } \\
\text { Unskilled } \\
\text { Skilled } \\
\text { Service } \\
\text { Unemployed }\end{array}$ & $\begin{array}{c}29 \\
32 \\
9 \\
7 \\
11\end{array}$ & $\begin{array}{c}30 \\
31 \\
11 \\
9 \\
7\end{array}$ & 2.586 & 160 & $\begin{array}{c}0.629 \\
\text { NS }\end{array}$ \\
\hline $\begin{array}{l}\text { Family income } \\
\text { (in Rupees) }\end{array}$ & $\begin{array}{c}<5000 \\
5001-10000 \\
>10000\end{array}$ & $\begin{array}{c}37 \\
42 \\
9\end{array}$ & $\begin{array}{l}34 \\
41 \\
13\end{array}$ & 1.38 & 160 & $\begin{array}{c}0.501 \\
\text { NS }\end{array}$ \\
\hline
\end{tabular}

Table 1: Demographic characteristics of alcohol dependence patients $(n=88)$ and control subjects $(n=88)$.

\begin{tabular}{|c|c|c|c|}
\hline \multirow{2}{*}{ Variable } & \multicolumn{3}{|c|}{ Alcohol dependence patients } \\
\cline { 2 - 4 } & Control & Number & Percent \\
\hline Age at onset of alcohol & $<20$ & 33 & 37.50 \\
consumption & $21-30$ & 51 & 57.95 \\
(in years) & $31-40$ & 4 & 4.54 \\
\hline & $1-5$ years & 2 & 2.27 \\
Duration of alcohol & $6-10$ & 14 & 15.91 \\
consumption & $11-15$ & 29 & 32.95 \\
(in years) & $16-20$ & 22 & 25.00 \\
& $>20$ & 21 & 23.86 \\
\hline
\end{tabular}

Table 2: Characteristics of alcohol use in patients with alcohol dependence.

\begin{tabular}{|c|c|c|c|c|}
\hline $\begin{array}{l}\text { Comorbid } \\
\text { Psychiatric } \\
\text { disorders }\end{array}$ & $\begin{array}{c}\text { Alcohol } \\
\text { dependent } \\
\text { Patients(n=88) } \\
N(\%)\end{array}$ & $\begin{array}{c}\text { Normal } \\
\text { Controls } \\
(n=88) \\
N(\%)\end{array}$ & \begin{tabular}{|c} 
Fishers exact \\
test/chi square \\
test \\
P
\end{tabular} & $\mathbf{P}$ \\
\hline Dementia & $2(2.27)$ & 0 & 0.497 & NS \\
\hline Schizophrenia & $2(2.27)$ & 0 & 0.497 & NS \\
\hline Psychosis NOS & $2(2.27)$ & 0 & 0.497 & NS \\
\hline Mania & $3(3.41)$ & 0 & 0.246 & NS \\
\hline Depression & $9(10.23)$ & 0 & 0.003 & $<0.05$ \\
\hline Dysthymia & $4(4.55)$ & $1(1.14)$ & 0.367 & NS \\
\hline Panic disorder & $4(4.55)$ & $1(1.14)$ & 0.367 & NS \\
\hline $\begin{array}{l}\text { Social Anxiety } \\
\text { disorder }\end{array}$ & $1(1.14)$ & $1(1.14)$ & 1 & NS \\
\hline GAD & $2(2.27)$ & $1(1.14)$ & 1 & NS \\
\hline $\begin{array}{l}\text { Mixed anxiety } \\
\text { and depression }\end{array}$ & $7(7.95)$ & $1(1.14)$ & 0.64 & NS \\
\hline $\begin{array}{l}\text { Adjustment } \\
\text { disorder }\end{array}$ & $7(7.95)$ & $1(1.14)$ & 0.64 & NS \\
\hline $\begin{array}{c}\text { Adult attention } \\
\text { deficit } \\
\text { hyperactivity } \\
\text { disorder }\end{array}$ & $1(1.14)$ & 0 & 1 & NS \\
\hline Total & $41(46.59)^{*}$ & $6(6.82)$ & & 0.0001 \\
\hline
\end{tabular}

Table 3: Comorbid psychiatric disorders in alcohol dependence syndrome patients.

population of India. This group of persons is usually underrepresented in hospital based studies.
The mean $( \pm$ SD) age of our patients $(40.86 \pm 10.72)$ and was similar to few previous Indian studies [17-20] The age of onset of alcohol use was similar to few earlier studies $[17,20]$ but less than in other studies $[18,19]$. In agreement with earlier Indian studies all the subjects were male [15-20].

The most important finding of the present study was that $46.59 \%$ $(n=41)$ of the alcohol dependent patients met the diagnostic criteria for at least one comorbid psychiatric disorder compared to $6.82 \%$ of the normative controls. The difference was highly statistically significant. This finding is congruent with a recent Indian study in a similar setting, [20] though other studies reported higher comorbidity [1519]. These differences could be due to differences in sample size and methods of diagnosis. Evaluation of thirty alcohol dependence patients who presented in Psychiatry outdoor clinic with SCID-I (structured clinical interview for DSM-IV Axis-I diagnosis) revealed an overall psychiatric comorbidity of $76.6 \%$ [16]. Similarly another study on 37 alcohol dependence patients also found a psychiatric comorbidity of $64.8 \%$ using the SCID-I [19]. Another study of 100 alcohol dependence patients using the present state examination also found a high prevalence of $71 \%$ [17] probably because in the absence of a mental hospital nearby this center catered to all types of psychiatric patients. The high prevalence of $81 \%$ was due to the fact that it was done at a mental hospital which mainly caters to patients with psychoses and severe mood disorders [15].

Out of 41 alcoholics with comorbid disorders in the present study, 38 had one comorbid disorder while 3 had two comorbid disorders. This finding is also in agreement with earlier Indian studies $[19,20]$. The prevalence of bipolar disorder in our study was $3.41 \%$. This finding is in agreement with a number of earlier Indian studies that reported a very low prevalence $(0 \%$ to $16 \%)$ of bipolar disorder in alcohol dependence patients $[15-17,20]$. However contrary to our findings one study found bipolar disorder to be the commonest comorbidity (20.4\%) [18]. The authors mentioned that the age onset of alcohol dependence in their sample was later than the usual age of onset for bipolar disorder. Therefore it is possible that the patients with alcohol dependencebipolar comorbidity developed bipolar disorder first and then only developed alcohol dependence. However, they had not looked at the temporal association of the two disorders in their study.

Unipolar depression was diagnosed in $10.23 \%$ of our patients with alcohol dependence and was the commonest comorbid psychiatric disorder. This finding is in agreement with a few Indian studies $[15,18,20]$ though some other studies have documented higher prevalence of $26 \%$ and $33 \%[17,19]$. The prevalence of anxiety disorders in our study was $15.9 \%$ which is in agreement with few earlier studies $[17,18,20]$ though one study reported high prevalence of $45 \%$ for anxiety disorders [19].

In the largest study to date the 2001-2002 National Epidemiologic Survey on Alcohol and Related Conditions, 43,093 participants aged 18 years or older from United States were evaluated with face-to-face interview. The study found that major mood and anxiety disorders that develop independently of acute intoxication and withdrawal are fairly common. Comorbid psychiatric disorders among subjects having AUD included anxiety disorders (36.9\%) and major mood disorder (29.2\%), clearly indicating that along with treatment of alcohol dependence these individuals would benefit from treatment of comorbid anxiety or mood disorder [16]. The prevalence of schizophrenia (2.27\%) and other psychoses (2.27) in our study was rather low. This finding is in agreement with few earlier studies $[17,18,20]$ but others reported much higher prevalence ranging from $11 \%$ to $25 \%[15,16,19]$. However, the prevalence was much less than in the ECA study in which the lifetime 
rate of comorbid schizophrenia in subjects with alcohol dependence was $24 \%$ [10]. The reasons for this could be that from our area patients with serious mental illness are usually taken to the state mental hospital, and only patients with minor disorders and substance use report to our center. The presence comorbid psychiatric disorders in alcohol dependent patients is associated increased utilization of hospital facilities, [26] reduced treatment for alcohol dependence, [27] and worse prognosis as compared to alcohol-dependent patients without dual diagnosis [28]. For successful management of these patients equal attention must be paid to treatment of alcohol dependence and the comorbid psychiatric disorder.

\section{Limitations}

This study had certain limitations. The sample size was modest and it was done at only two sites. Further being a hospital based study the results may not be generalized to the population. Future studies should also include psychometric tools to characterize alcohol use.

\section{Conclusion}

Individual with alcohol dependence have a high prevalence of comorbid psychiatric disorders. Correct assessment and evaluation of co-morbid Psychiatric Disorders in alcohol dependent individuals would be useful in planning comprehensive management of these conditions.

\section{References}

1. Donadon MF, Osório FL (2016) Personality traits and psychiatric comorbidities in alcohol dependence. Braz J Med BiolRes 49: e5036.

2. BodenJM, Fergusson DM (2011) Alcohol and depression. Addiction 106: 906 914

3. Morley KC, Baillie A, Sannibale C, Teesson M, Haber PS (2013) Integrated cares for comorbid alcohol dependence and anxiety and/or depressive disorder: Study protocol for an assessor-blind, randomized controlled trial. Addict Sci Clin Pract 8: 19.

4. Whiteford HA, Degenhardt L, Rehm J, Baxter AJ, Ferrari AJ, et al. (2013) Global burden of disease attributable to mental and substance use disorders: findings from the Global Burden of Disease Study 2010. Lancet 382: 1575-1586.

5. Rehm J, Mathers C, Popova S, Thavorncharoensap M, Teerawattananon Y, et al. (2009) Global burden of disease and injury and economic cost attributable to alcohol use and alcohol-use disorders. Lancet 373: 2223-2233.

6. Kohn R, Saxena S, Levav I, Saraceno B (2004) The treatment gap in mental health care. Bull World Health Organ 82: 858-866.

7. Subir KD, Balakrishnan V, Vasudevan DM (2006) Alcohol: Its health and social impact in India. Natl Med J India 19: 94-99.

8. Alves H, Kesslerb F, Rattoc LRC (2004) Comorbidity: Alcohol use and other psychiatric disorders. Rev Bras Psiquiatr 26: 51-53

9. Regier DA, Farmer ME, Rae DS, Locke BZ, Keith SJ, et al. (1990) Comorbidity of mental disorders with alcohol and other drug abuse. Results from the Epidemiologic Catchment Area (ECA) Study. JAMA 264: 2511-2518.

10. Kessler RC, Crum RM, Warner LA, Nelson CB, Schulenberg J, et al. (1997) Lifetime co-occurrence of DSM-III-R alcohol abuse and dependence with othe psychiatric disorders in the National Comorbidity Survey. Arch Gen Psychiatry 54: 313-321.

11. Weaver T, Madden P, Charles V, Stimson G, Renton A, et al. (2007) Comorbidity of substance misuse and mental illness in community mental health and substance misuse services. Br J Psychiatry 183: 304-313.

12. Nubukpo P, Girard M, Sengelen JM, Bonnefond S, Varnoux A, et al. (2016) A prospective hospital study of alcohol use disorders, comorbid psychiatric conditions and withdrawal prognosis. Ann Gen Psychiatry 15: 22.

13. Pereiro C, Pino C, Flórez G, Arrojo M, Becoña E, et al. (2013) Psychiatric Comorbidity in Patients from the Addictive Disorders Assistance Units of Galicia: The COPSIAD Study. PLoS ONE 8: e66451.

14. Rush B, Koegl J (2008) Prevalence and profile of people with co-occurring mental and substance use disorders within a comprehensive mental health system. Can J Psychiatry 53: 810-821.

15. Shantna K, Chaudhury S, Verma AN, Singh AR (2009) Comorbid psychiatric disorders in substance dependence patients: A control study. Ind Psychiatry J 18: 84-87.

16. Vohra AK, Yadav BS, Khurana H (2003) A study of psychiatric comorbidity in alcohol dependence. Indian J Psychiatry 45: 247-250.

17. Singh NH, Sharma SG, Pasweth AM (2005) Psychiatric co-morbidity among alcohol dependents. Ind J Psychiatry 47: 222-204.

18. Kattukulathil S, Kallivayalil RA, George R, Kazhungil F (2015) Psychiatric comorbidity in alcohol dependence: a cross-sectional study in a tertiary care setting. Kerala Journal of Psychiatry 28: 156-160.

19. Kumar V, Dalal PK, Trivedi JK, Kumar P (2010)A study of psychiatric comorbidity in alcohol dependence. Delhi Psychiatry Journal 13: 291-293.

20. Singh A, Kumar S, Sharma CS, Dixit V, Srivastava RK, et al. (2016) Othe psychiatric comorbidities in male patients of alcohol dependence syndrome: a cross sectional study. Indian Journal of Basic and Applied Medical Research 5: 828-838.

21. American Psychiatric Association (1994) Diagnostic and Statistical Manual of Mental Disorders, Fourth Edition. APA, Washington, DC

22. Sheehan DV, Lecrubier Y, Harnett-Sheehan K, Janavs J, Weiller E, et al (1997) The validity of the MINI International Neuropsychiatric Interview (MINI): According to the SCID-P. Eur Psychiatry 12: 232-241.

23. Sheehan DV, Lecrubier Y, Harnett-Sheehan K, Amorim P, Janavs J, et al. (1998) The Mini International Neuropsychiatric Interview (MINI): The development and validation of a structured diagnostic psychiatric interview. J Clin Psychiatry 59: 22-33.

24. Chukwujekwu CD (2017) Commentary on the comorbidity of alcohol use disorder and depression among patients attending a tertiary hospital in the Niger Delta Region of Nigeria. J Addict Res Ther 8: 3.

25. Klimkiewicz A, Klimkiewicz J, Jakubczyk A, Kieres-Salomoński I, Wojnar M (2015) Comorbidity of alcohol dependence with other psychiatric disorders. Part II. Pathogenesis and treatment. Psychiatr Pol 49: 277-294.

26. Stewart SH (2007) Alcoholics in acute medical settings have increased risk for other drug, mood, and personality disorders. Int J Psychiatry Med 37: 59-67.

27. Verheul R, KranzlerHR, Poling J, Tennen H, Ball S, et al. (2000) Co-occurrence of Axis I and Axis II disorders in substance abusers. Acta Psychiatr Scand 101 110-111.

28. Di Sclafani V, Finn P, Fein G (2007) Psychiatric comorbidity in long-term abstinent alcoholic individuals. Alcohol Clin Exp Res 31: 795-803. 